\title{
RECENT DEVELOPMENTS IN THE FIELD OF ORGANIC DERIVATIVES OF GROUP IV B ELEMENTS
}

\author{
WiLHELM P. NEUMANN
}

Universität Dortmund, D4600 Dortmund-Hombruch, August-Schmidt-Straße 6

\begin{abstract}
Formation of perarylated cyclosilanes and cyclogermanes from diaryl dihalides and lithium, sodium or sodium-naphthalene is assumed to proceed by a stepwise catenation of the Wurtz type. Degradation in the mass spectrometer takes place mainly by elimination of respectively carbene-like $\mathrm{Ar}_{2} \mathrm{Si}$ or $\mathrm{Ar}_{2} \mathrm{Ge}$ moieties.

Formation of free radicals from organotin compounds by radical breakdown of different bonds around the tin atom is investigated. A table with present 'best values' for $D_{\mathrm{Sn}-\mathrm{x}}$ is given. They vary in the range between $\sim 35(\mathrm{Sn}-\mathrm{H})$ and $95(\mathrm{Sn}-\mathrm{OCOR}) \mathrm{kcal} / \mathrm{mole}$. Organotin hydrides are very strong radical scavengers.

In the chemistry of stannyl radicals $R_{3} \mathrm{Sn}$, various substitutions of the type $S_{R} 2$ have been found. With diacyl peroxides and peresters, the peroxide bridge is attacked. Attention has been given to the different transition states. As shown by the influence of $\pi$-electron density, $\mathrm{R}_{3} \mathrm{Sn}$ - is strongly nucleophilic. Some azo compounds $\mathrm{R}-\mathrm{N}=\mathrm{N}-\mathrm{X}-\mathrm{R}^{\prime}\left(\mathrm{X}=\mathrm{O}, \mathrm{S}, \mathrm{SO}_{2}, \mathrm{NR}^{\prime \prime}\right)$, hydrazines and pentaz-dienes are degraded rapidly and by a similar mechanism.
\end{abstract}

\section{A. INTRODUCTION}

IN THE last 15 years, an increasing number of observations have led to the conclusion that some covalent bonds around the elements of group IV B have a surprisingly high reactivity. New chemistry of organic derivatives of this group has been developed. The bonds $(\mathrm{M}=\mathrm{Si}, \mathrm{Ge}, \mathrm{Sn}, \mathrm{Pb}) \mathrm{M}-\mathrm{H}$, $\mathrm{M}-\mathrm{N}$ and $\mathrm{M}-\mathrm{O}$ merit special attention here, but a number of $\mathrm{M}-\mathrm{C}$ and $\mathrm{M}$-metal bonds are also of new importance. This has led not only to considerable progress in preparative chemistry, but also to a better understanding of reaction mechanisms. In this connection, it should not be forgotten that carbon is the first element of group IV B, and that conclusions from theoretical organic chemistry have stimulated some of the investigations in the field to be considered here.

Some recent developments made by the author's group will be reported, coming from the Institute of Organic Chemistry of the University of Giessen up to spring 1969, and currently from the Laboratories of Organic Chemistry of the new University of Dortmund. 


\section{B. NEW EVENTS IN THE CHEMISTRY OF CYCLOSILANES AND CYCLOGERMANES}

Perphenylated cyclo-silanes and -germanes with 4-, 5- or 6-membered rings became known in recent years through the work of Professor Henry Gilman and his co-workers ${ }^{1}$ as well as that of my student $\mathbf{K}$. Kühlein and myself $f^{2,3}$. We sought to bring more insight into some details of formation and of behaviour of these peculiar compounds. For these studies, my student Michael Richter ${ }^{4}$ took the $p$-tolyl residue bound to $\mathrm{Si}$ or Ge. Using the classical method, he prepared the 4-, 5- and 6-membered rings, starting from either $p-\mathrm{Tol}_{2} \mathrm{SiCl}_{2}$ or $p-\mathrm{Tol}_{2} \mathrm{GeCl}_{2}$. (The latter was prepared in satisfying purity from the dihydride with carbon tetrachloride.) (See Scheme 1.)

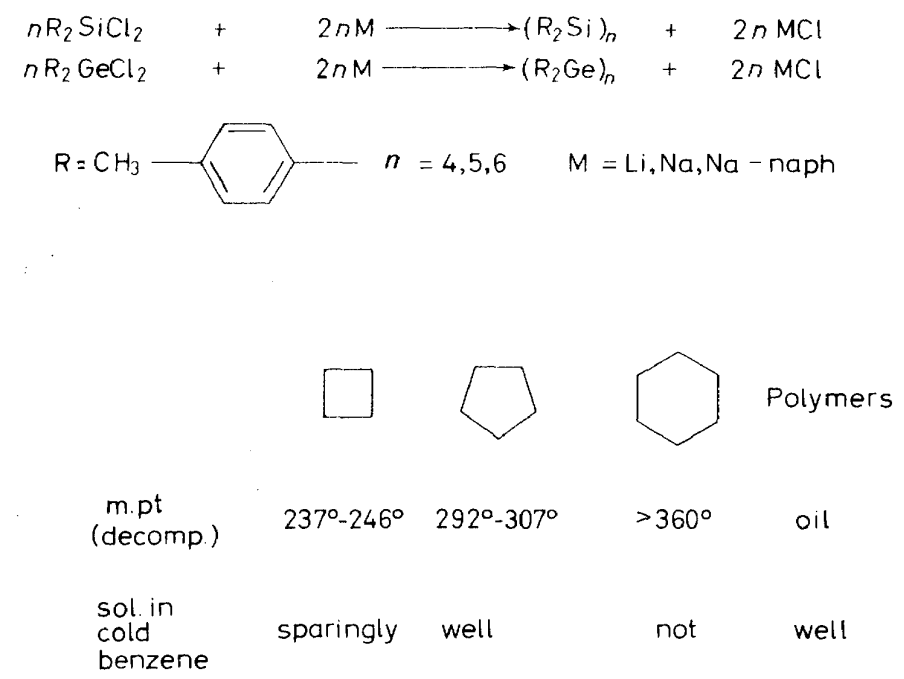

Scheme 1 (after Richter and Neumann, 1969)

It is surprising that the melting points and solubilities shown in Scheme 1 are quite similar or even identical for the corresponding silyl and germyl rings. The same can be seen by comparing corresponding $p$-tolyl and phenyl derivatives ${ }^{1,2}$.

Scheme 2 is concerned with the mechanism of ring formation. It could be thought - and Russian workers drew attention to this in the case of similar tin compounds ${ }^{5}$ - that carbene-like silylenes or germylenes work as intermediates here.

They may arise from compounds, e.g. $\mathrm{R}_{2} \mathrm{Ge}(\mathrm{Cl}) \mathrm{M}$ by $\alpha$-elimination, a type of reaction well known in the chemistry of carbenes. If this takes place, a germylene should appear (and its polymers too) by reacting $\mathbf{R}_{\mathbf{2}} \mathbf{G e C l}_{\mathbf{2}}$ with $\mathrm{R}^{\prime} \mathrm{Li}$, see Scheme 2 . However, we failed to detect any trace of polymeric $\left(\mathrm{R}_{2} \mathrm{Ge}\right)_{n}$ or other following products, but found a nearly quantitative yield of $\mathrm{R}_{2} \mathrm{Ge}\left(\mathrm{R}^{\prime}\right) \mathrm{Cl}$.

For the mechanism, we prefer a stepwise prolongation of the chain by reactions of the Wurtz type. Polymers can be formed; but, if there is a proper steric conformation, ring closure occurs. With our bulky $p$-tolyl 

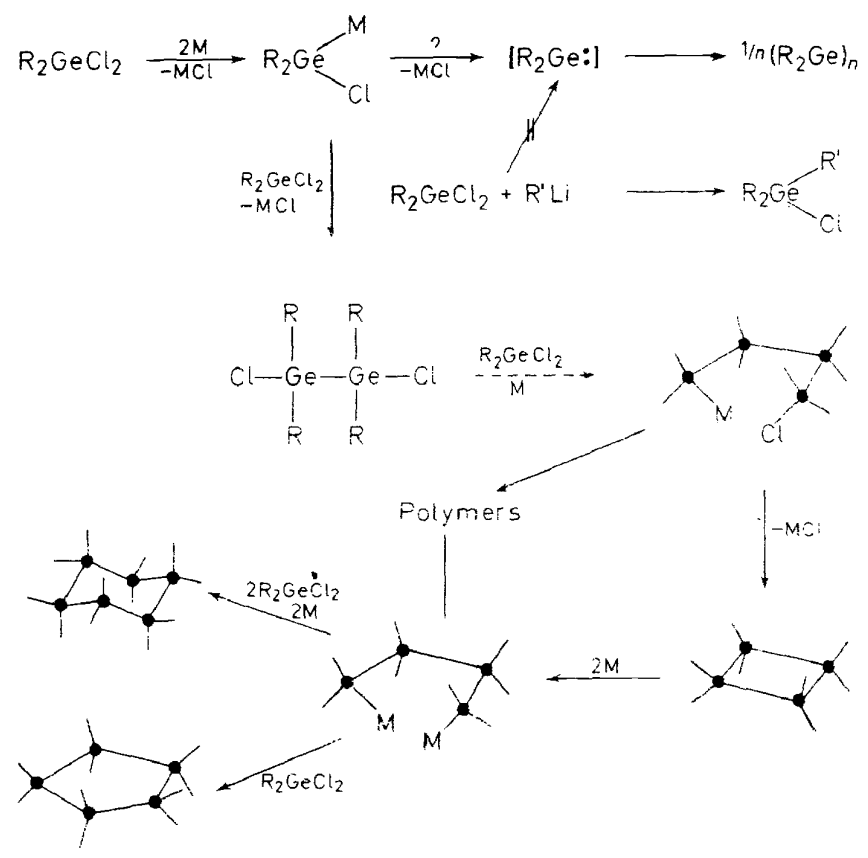

Scheme 2

residues, the horse-shoe conformation (Scheme 2) is a preferred one, and the 4-membered ring is formed first. If one provides a lack of reactive metal atoms--easy to establish when using sodium turnings or lithium wirethis product can be isolated in yields up to 60 per cent. Moreover, it is split off quickly by excess of alkali metal atoms, forming both polymers and a mixture of 5- and 6-membered rings. The 4-membered ring disappears from the reaction mixture. When we used a very finely divided suspension of sodium ( 5 microns) or, even more effective, a sodium-naphthalene solution, we could not detect any $\mathrm{Ge}_{4}$-ring, but found only the 5- and 6membered ones.

Up to now, there is no proof of the occurrence of carbene-like silylenes and germylenes as intermediates in solution. But in a high vacuum and caused by electron impact, they do occur. Using a Varian $\mathrm{CH} 5$ mass spectrometer and its normal inlet equipment, we found the following series of degradation products ${ }^{4,6}$, see Scheme 3. (The germanium derivatives are shown as an example here.) The molecular peaks can be seen, in the case of $\mathrm{Ge}_{5}$ and $\mathrm{Ge}_{4}$, with striking intensity. This means that the cyclic molecules are of considerable stability.

All cations found in the 6-membered Ge-ring are compiled in Scheme 4 to propose a main degradation pathway. Carbene-like $\mathrm{Tol}_{2} \mathrm{Ge}$ is the main leaving group. In addition splitting of tolyl residues occurs, as well as splitting of $\mathrm{Tol}_{3} \mathrm{Ge}$ and of TolGe residues ${ }^{6 \mathrm{a}}$. The latter indicates a type of splitting with migration of aryl groups : 
WILHELM P. NEUMANN

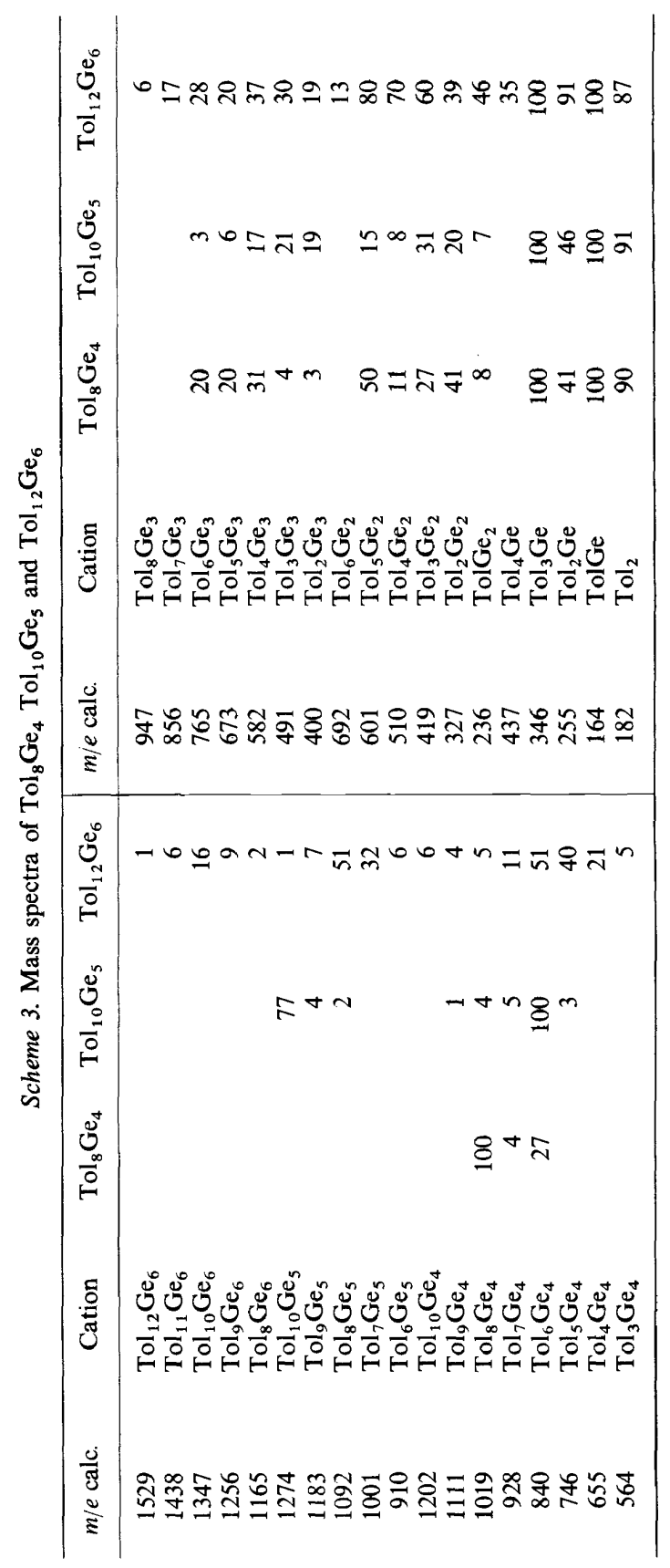


ORGANIC DERIVATIVES OF GROUP IVB ELEMENTS
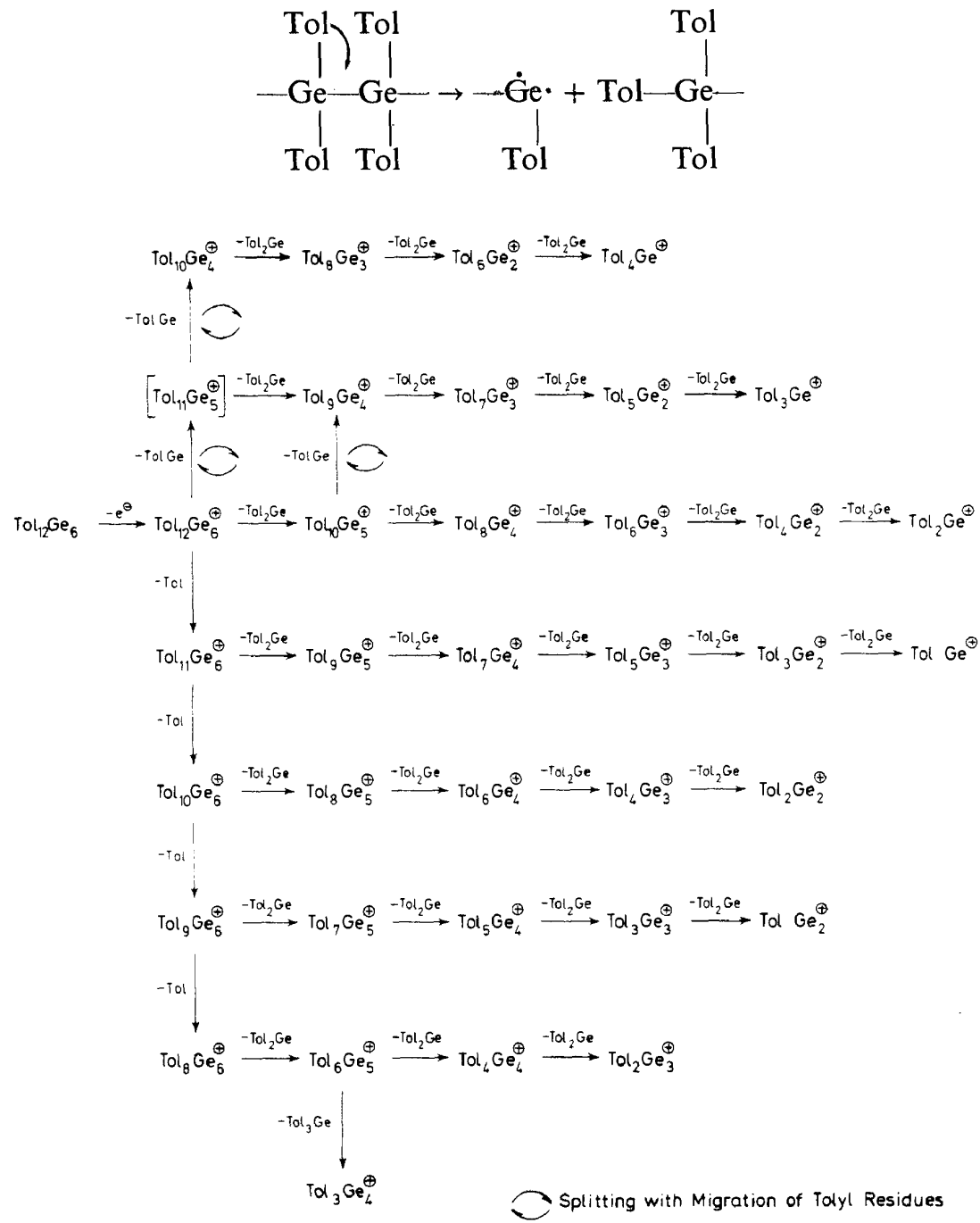

Scheme 4. Degradation of cyclo- $\mathrm{Tol}_{12} \mathrm{Ge}_{6}$ in the mass spectrometer

Some cations with very low tolyl contents are also worth mentioning. It seems that splitting of electrons by electron impact concerns not only $\mathrm{Ge}-\mathrm{Ge}$ bonds $(45 \mathrm{kcal})^{7}$ and $\mathrm{Ge}-\mathrm{C}$ bonds, but also electrons from the aromatic systems of tolyl residues $(203 \mathrm{kcal})^{8}$ and those from lower orbitals of $\mathrm{Ge}$ atoms $(191-213 \mathrm{kcal})^{9}$ (See, e.g., $\mathrm{Tol}_{6} \mathrm{Ge}_{2}^{\oplus}$ and $\mathrm{Tol}_{4} \mathrm{Ge}^{\oplus}$ ).

\section{FORMATION OF FREE RADICALS FROM ORGANOTIN COMPOUNDS}

The chemistry of free radicals has made considerable progress in organic chemistry during the last few years. It is not surprising, therefore, that 
organometallic chemistry, which was thought for a long time to be nearly exclusively a chemistry of ions, has been reinspected recently for the occurrence of radicals.

My group was interested especially in studying organotin radicals ${ }^{12}$. Some observations concerning silyl and germyl radicals will be reported in a short communication during this meeting.

Around the tin atom several bonds are susceptible for radical breakdown. It would be desirable to have exact values for bond dissociation energies. One way of determining these values may be the measurement of appearance potentials for corresponding ions in the mass spectrometer and then, using a set of thermochemical data, calculation of the desired dissociation energy. Measuring of appearance potentials of rather heavy ions, like those with tin atoms, is not easy and possibly not free from errors, but should eventually be effected with satisfying results. But, unfortunately, different sets of thermochemical data are needed for the final calculations. The discussion about which ones are correct is as yet unsettled, to the author's knowledge. The first published dissociation energies ${ }^{10}$ calculated from appearance potentials, therefore, are rather high and, at least in my experience, not in good agreement with chemical evidence. In the author's group an internal table of dissociation energies is used, Scheme 5. It is based on published thermochemical values, recalculation of several other data ${ }^{10}$, and chemical experience ${ }^{11}$.

Scheme 5. Dissociation energies $D(\mathrm{kcal} / \mathrm{mole})$ for compounds $\left(\mathrm{CH}_{3}\right)_{3} \mathrm{Sn}-\mathrm{X}$

\begin{tabular}{lc|lc}
\hline $\mathrm{X}$ & $D(\mathrm{kcal} / \mathrm{mole})$ & $\mathrm{X}$ & $D(\mathrm{kcal} / \mathrm{mole})$ \\
\hline $\mathrm{CH}_{3}$ & 55 & $\mathrm{NR}_{2}$ & $(65$ to 70$)$ \\
$\mathrm{C}_{2} \mathrm{H}_{5}$ & 50 & $\mathrm{O}-\mathrm{COR}^{\prime}$ & $\sim 95$ \\
$\mathrm{CH}=\mathrm{CH}_{2}$ & 60 & $\mathrm{Cl}$ & 85 \\
$\mathrm{CH}_{2}-\mathrm{CH}=\mathrm{CH}_{2}$ & $\sim 37$ & $\mathrm{Br}$ & 76 \\
$\mathrm{CH}_{2}-\mathrm{C}_{6} \mathrm{H}_{5}$ & 39 & $\mathrm{I}$ & 62 \\
$\mathrm{C}_{6} \mathrm{H}_{5}$ & 63 & & \\
$\mathrm{Sn}\left(\mathrm{CH}_{3}\right)_{3}$ & 57 & & \\
$\mathrm{H}$ & $\sim 35$ & & \\
\hline
\end{tabular}

Of course, some of these values are empirical or at least semi-empirical. Good support is given by recent measurements ${ }^{9}, 10 a$, which give, for example, for $\left(\mathrm{CH}_{3}\right)_{3} \mathrm{Sn}-\mathrm{CH}_{3} 61 \pm 5$ or $60.5 \pm 2 \mathrm{kcal}$, which is in rather good agreement with the old thermochemical value of $55 \pm 5 \mathrm{kcal}$, see Scheme 5 .

\section{NEW EVENTS IN THE CHEMISTRY OF STANNYL RADICALS}

Stannyl radicals $\mathrm{R}_{3} \mathrm{Sn} \cdot(\mathrm{R}$ mostly $\mathrm{Bu}, \mathrm{Et}$ or $\mathrm{Me}$ ) have proved themselves to be useful reagents for studying radical reaction mechanisms. The author's group has an intense interest in this field of research ${ }^{12-14}$. Some examples of new developments will be given here.

Benzoyl peroxide is degraded by organotin hydrides very quickly by the way of a radical chain mechanism. Compared with this, the very efficient known inducing compounds like dibutyl ether are rather ineffective, see Scheme 6. 


\section{ORGANIC DERIVATIVES OF GROUP IVB ELEMENTS}

Scheme 6. Half-life time of benzoyl peroxide, $02 \mathrm{M}$ in benzene

\begin{tabular}{lcr}
\hline $\begin{array}{c}\text { Inducing compound } \\
0.4 \mathrm{M}\end{array}$ & Temperature, ${ }^{\circ} \mathrm{C}$ & $t_{\frac{1}{2}}, \min$ \\
\cline { 3 - 3 } & 80 & 240 \\
Without & 75 & 345 \\
$\mathrm{C}_{4} \mathrm{H}_{9}-\mathrm{O}-\mathrm{C}_{4} \mathrm{H}_{9}$ & 60 & $\sim 1800$ \\
$\mathrm{C}_{4} \mathrm{H}_{9}-\mathrm{O}-\mathrm{C}_{4} \mathrm{H}_{9}$ & 60 & 14 \\
$\left(\mathrm{C}_{2} \mathrm{H}_{5}\right)_{3} \mathrm{SnH}$ & 50 & 53 \\
$\left(\mathrm{C}_{2} \mathrm{H}_{5}\right)_{3} \mathrm{SnH}$ & & \\
\hline
\end{tabular}

Stannyl radicals are the attacking species. Scheme 7 shows what is going on with acetyl benzoyl peroxide, which has been selected for detailed studies $^{14}$.

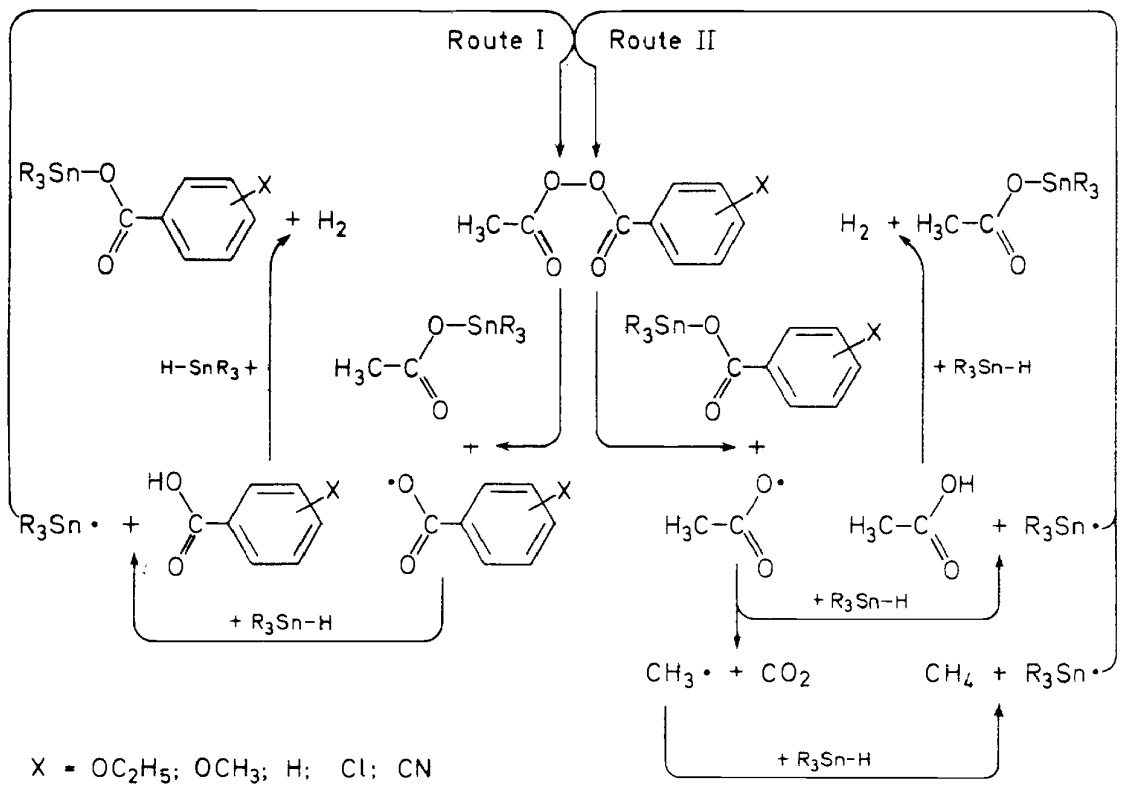

Scheme 7

The peroxide bridge is attacked by a stannyl radical, but the two oxygen atoms are not equivalent, depending upon the nature of the substituent $\mathrm{X}$. The more electron withdrawing is $\mathrm{X}$, the more is Route II preferred by the stannyl radical, releasing an acetoxy radical, a part of which forms $\mathrm{CO}_{2}+$ $\mathrm{CH}_{4}$, see Schemes 7 and 8 .

Consideration of all the available facts leads to the ratio of Route I : Route II as set out in Scheme?.

A free radical always looks for places susceptible to radical attack (i.e. with high $F$-values, which may be given by HMO calculations). From the foregoing, however, it must be concluded that the stannyl radical is strongly 
WILHELM P. NEUMANN

Scheme 8 . Unsym. diacylperoxide, $023 \mathrm{~mol}$. in benzene +2 mole $\left(\mathrm{C}_{2} \mathrm{H}_{5}\right)_{3} \mathrm{SnH}, 600^{\circ}$, Yield of products

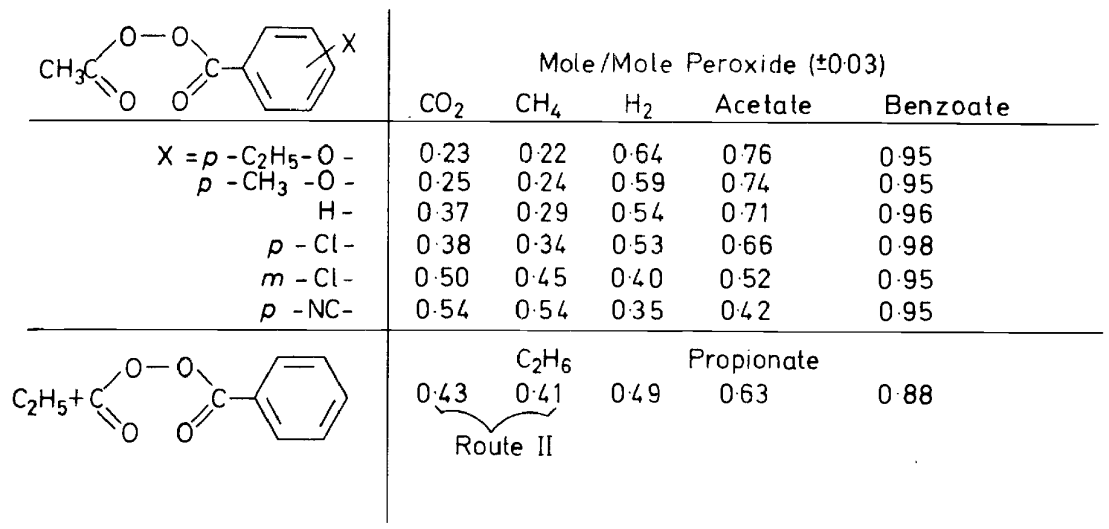
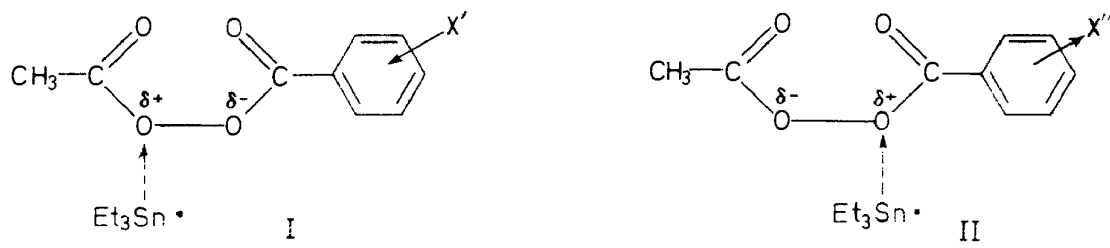

\begin{tabular}{|c|c|c|}
\hline Peroxide & I & II \\
\hline $\mathrm{CH}_{3} \mathrm{CO}-\mathrm{OO}-\mathrm{CO}-\mathrm{C}_{6} \mathrm{H}_{4}-\mathrm{OC}_{2} \mathrm{H}_{5}(\rho)$ & $70 \%$ & $30 \%$ \\
\hline $\mathrm{CH}_{3} \mathrm{CO}-\mathrm{OO}-\mathrm{CO}-\mathrm{C}_{6} \mathrm{H}_{4}-\mathrm{H}$ & $63 \%$ & $37 \%$ \\
\hline $\mathrm{CH}_{3} \mathrm{OO}-\mathrm{OO}-\mathrm{CO}-\mathrm{C}_{6} \mathrm{H}_{4}-\mathrm{Cl} \quad(p)$ & $56 \%$ & $44 \%$ \\
\hline $\mathrm{CH}_{3} \mathrm{CO}-\mathrm{OO}-\mathrm{CO}-\mathrm{C}_{6} \mathrm{H}_{4}-\mathrm{CN} \quad(p)$ & $36 \%$ & $64 \%$ \\
\hline
\end{tabular}

Scheme 9 (after Rübsamen, Neumann, Ra. Sommer, Frommer. Chem. Ber. 102, 1290 (1969)).

nucleophilic, always seeking the most electron-deficient place in those parts of a peroxide molecule susceptible to radical attack.

This is of interest, because most free radicals so far studied intensively are only slightly nucleophilic or even, generally, electrophilic.

Now, the transition state of the radical attack mentioned above should be considered, see Scheme 10. With a diacyl peroxide, only one set of products can be formed, as is known from many experiments made so far. It may be concluded, therefore, that there is only one way leading to them and only one transition state.

A different behaviour has been found with tert-butyl peresters ${ }^{15}$. On the one hand, the expected way with formation of stannyl ester and tert-butoxy radical (which undergoes further reactions) has been established. On the other hand induced fragmentation has been observed with evolution of 


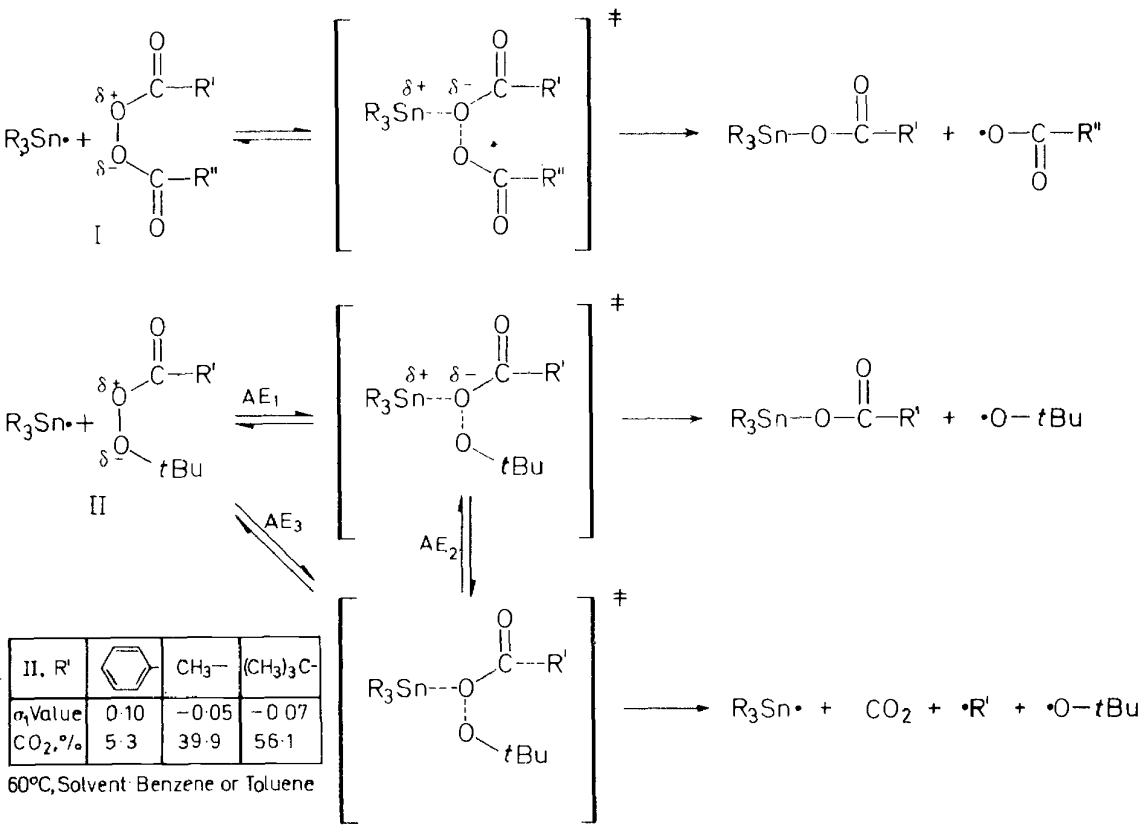

Scheme 10

carbon dioxide and typical products (the radicals undergo further reactions), as shown in Scheme 10. Again, stannyl radicals are the inducing agent, ending without being bound to any of the resulting products. They finally recombine to the distannane. This is a new type of reaction, apparently not yet studied. Stannyl radicals clearly work as catalysts here. The inducing power of stannyl radicals is illustrated by the half-life time of the peresters, which is decreased by a factor of about $10^{-3}$, compared with that of the corresponding spontaneous radical degradation. Therefore, two transition states can be assumed, as shown in Scheme 10. The lower one needs additional activation energy, $A E_{3}>A E_{1}$, and apparently is less polar. This can be concluded from the facts that at higher temperatures $\left(60^{\circ} \mathrm{C}\right)$ or in non-polar solvents much more carbon dioxide is evolved than at lower temperatures or in polar solven ts (isobutyronitrile). $\mathbf{R}^{\prime}$ in the perester II yields an additional influence by means of inductive effects : the higher the polarity of II, the more the 'normal way' is preferred. It should be mentioned that hitherto fragmentation was known for the pivalyl perester - but only at much higher temperatures-whereas it was uncertain for the acetic and was entirely unknown for the benzoic acid perester ${ }^{16}$.

An old question for chemists concerned with radical degradation of azo compounds is, whether this degradation can be only of first order, or whether it may be induced by any other compound. Until 1967, the answer was: no induction is possible. But then, new aspects could be revealed by means of stannyl radicals ${ }^{13}$. Scheme 11 shows some azo compounds of the types $\mathbf{R}-\mathbf{N}=\mathbf{N}-\mathrm{X}-\mathrm{R}^{\prime}$ and $\mathrm{R}-\mathrm{X}-\mathrm{N}=\mathrm{N}-\mathrm{X}-\mathrm{R}$, which are degraded 


\section{WILHELM P. NEUMANN}

quickly by stannyl radicals, with evolution of nitrogen. Some recent results in this field have been published by the author's group ${ }^{13}$.

Now, some further examples ${ }^{17}$ should be noticed: 1,3-diphenyl-3-benzoyltriazene, Scheme 12, and 1,4-diphenyl-1,4-dicyclohexyl-tetrazene, Scheme 13.

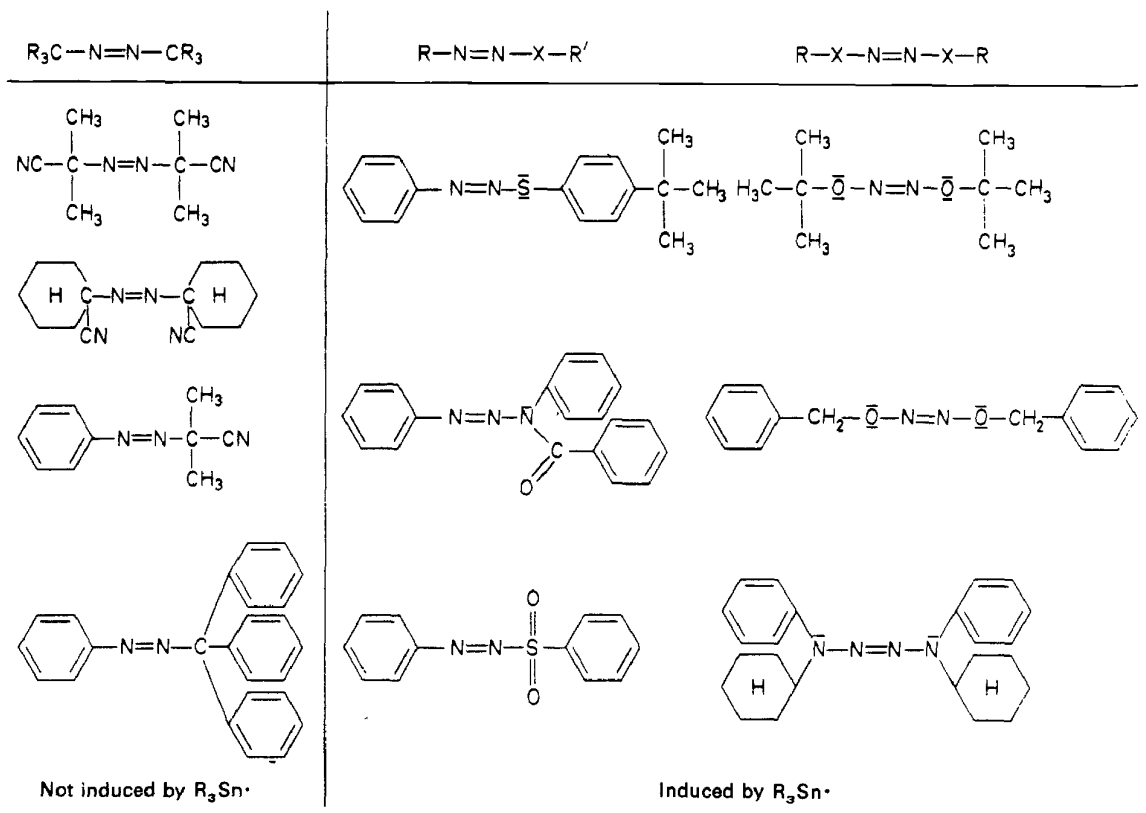

Scheme 11

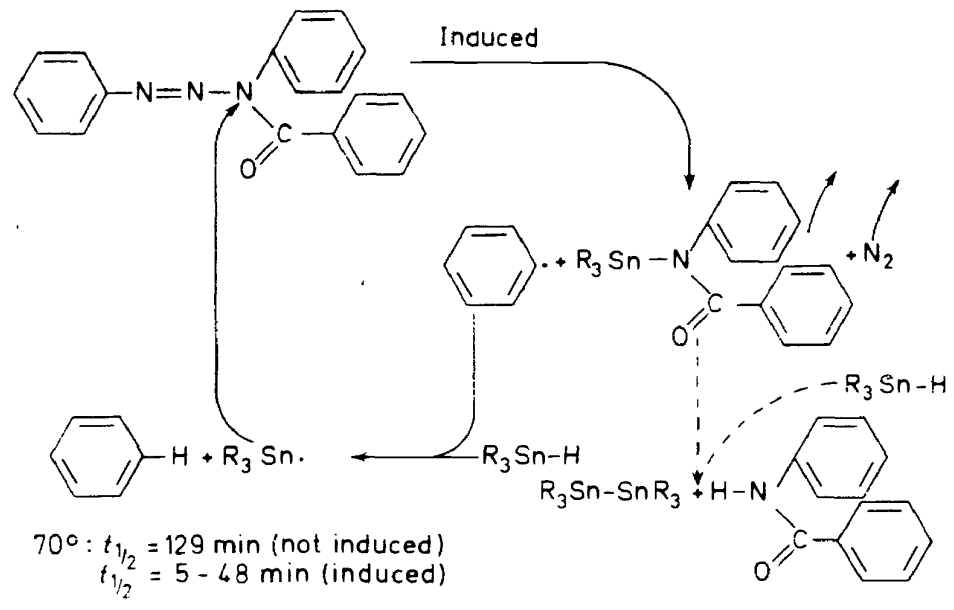

Scheme 12 


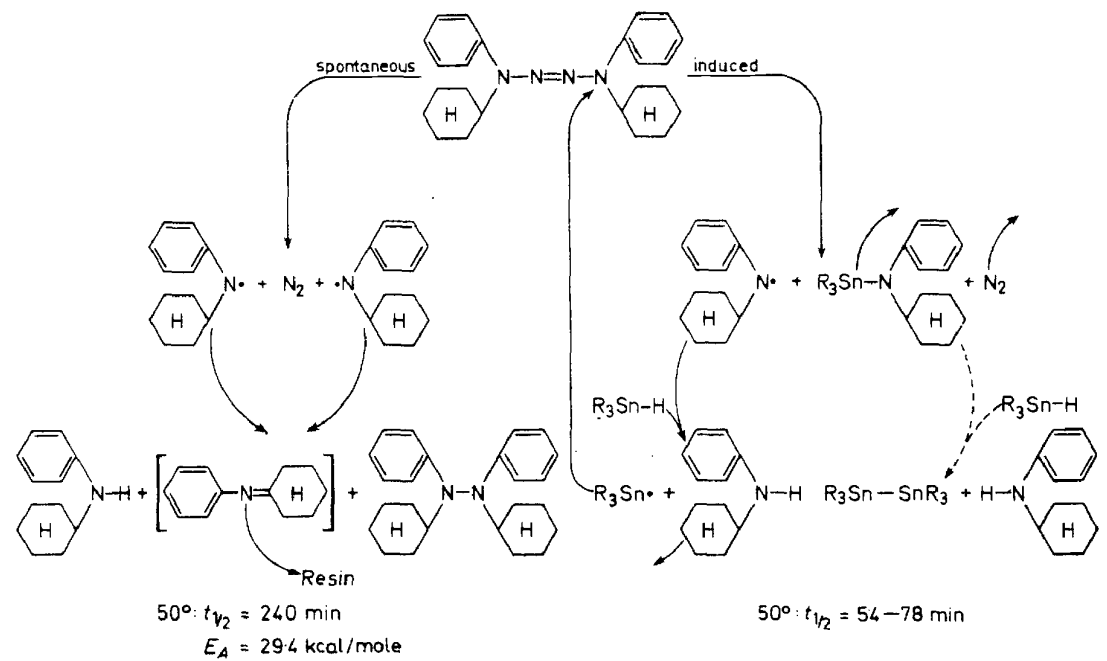

Scheme 13

All these induced degradations are radical reactions of the type $S_{R}$.

From investigation of a series of tetrazenes some facts governing the behaviour of the stannyl radical can be derived, see Scheme 14. As might be

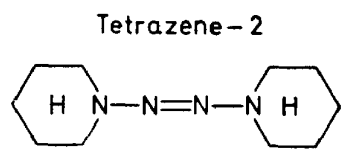

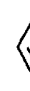
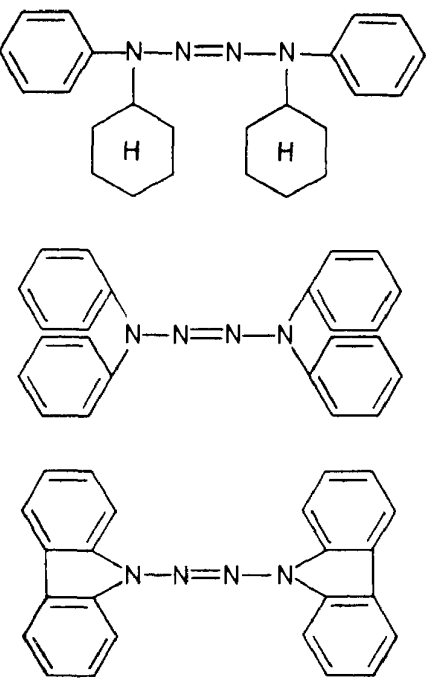

$\Delta H^{*}$ spontaneous $\mathrm{kcal} / \mathrm{mole}, 50^{\circ} \mathrm{C}$

36

28.7

$28 \cdot 9$

$\sim 39$

$\leqq 1.74$

1.74

\section{Electron density Degraded by} at $\mathrm{N}_{1}$ and $\mathrm{N}_{4} \quad \mathrm{R}_{3} \mathrm{Sn}$.

1.89

no

quick

very quick

Scheme 14 
expected, the activation enthalpy is important. The higher it is, the more unlikely it is for the attacking stannyl radical to be able to afford it. But another factor can be derived, too. The more electron density is withdrawn from $\mathrm{N}_{1}$ and $\mathrm{N}_{4}$, the easier these spots are attacked by the nucleophilic stannyl radical. This can best be seen by comparing the second with the third tetrazene ${ }^{18}$ in Scheme $14^{18}$.

Recently, reactions of stannyl radicals with further groups of organic compounds have been found. Two examples should be included here.

Tetraphenylhydrazine dissociates, as is well known, into two diphenylamine radicals. If one adds a radical scavenger (as was done by Hungarian workers ${ }^{19}$ ) the half-life time could be determined, see Scheme 15. But, organotin hydride works not only as radical scavenger here. The stannyl radicals resulting from scavenging steps, attack further hydrazine molecules, giving one mole of the stannylamine and, lastly, one mole of diphenylamine ${ }^{\mathbf{1 8}}$.

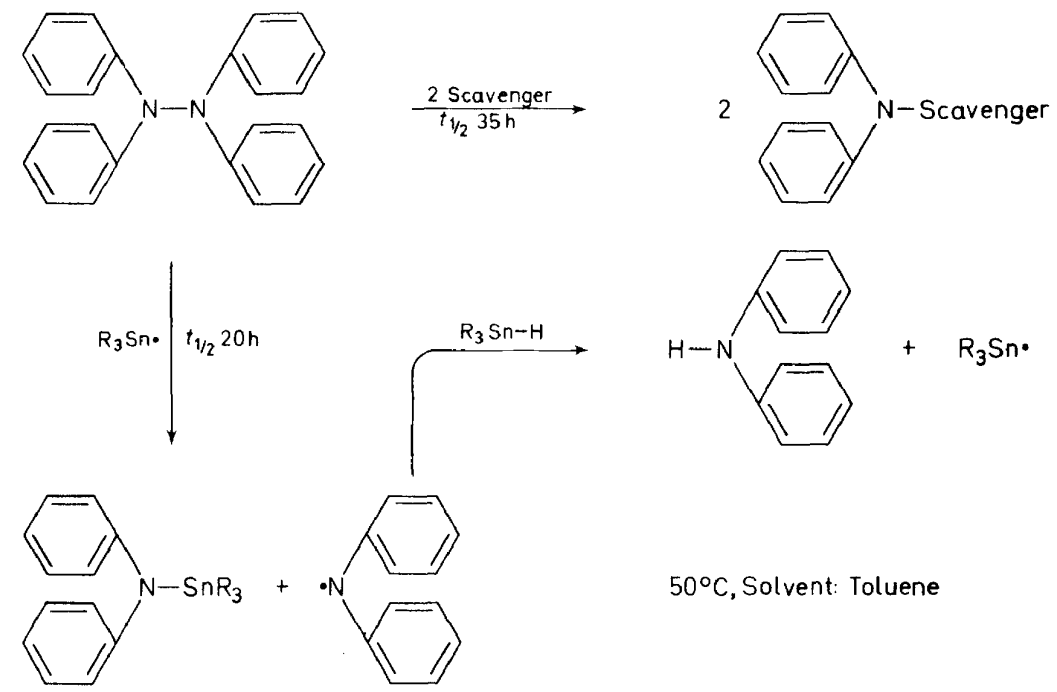

Scheme 15

A peculiar compound is the pentaz-diene ${ }^{19 a}$, shown in Scheme 16. It explodes violently at elevated temperature. We tried only once to take its melting point. But, at low temperature, it behaves quite nicely and can be investigated without trouble. The central nitrogen atom is of special interest here. It is influenced twice by the strongest electron-withdrawing group, the azo group. Therefore, its $\pi$-electron density must be very low, and an attack of the nucleophilic stannyl radical should be favoured. In fact, this can be observed $^{20}$.

The half-life time drops drastically from 1830 to about $60 \mathrm{~min}$, depending on the $\mathrm{R}_{3} \mathrm{Sn}-\mathrm{H}$ concentration. The resulting $\mathrm{N}$-stannyltriazene (or $\mathrm{N}$ stannyldiazoaminobenzene) is remarkably stable and can be distilled in vacuo without decomposition. Perhaps, there is pentacoordination around the tin atom, with the azo group working as donor. But, further investigation going on in the Dortmund Laboratories will possibly resolve this problem 


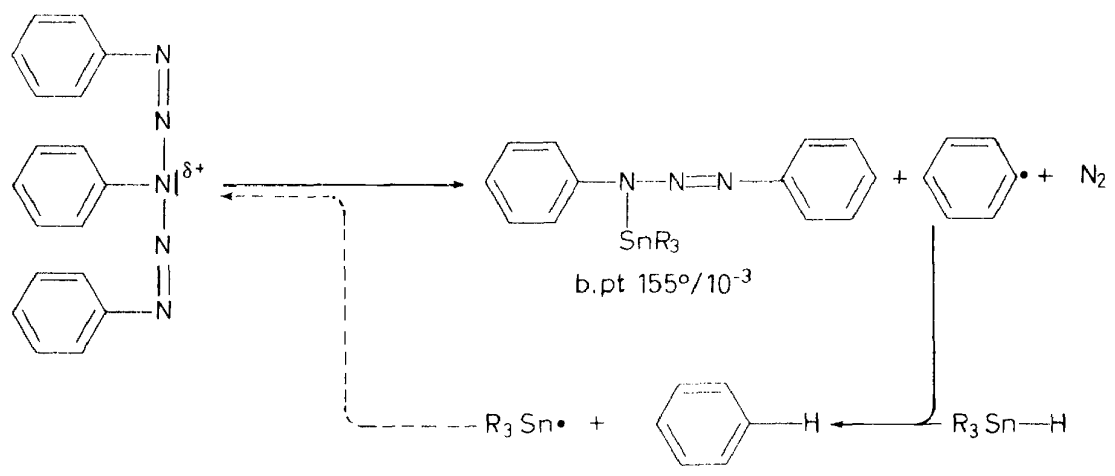

$-10^{\circ} \mathrm{C}$ in toluene; $t_{1 / 2}$ spont. $1830 \mathrm{~min}, t_{1 / 2} 1 \mathrm{nd} .60 \mathrm{~min}$

\section{Scheme 16}

fully. Stannyl radicals needed for the experiments referred to have been produced from organotin hydrides within the reaction mixture. Often it is advantageous to have these hydrides present for scavenging short-lived radicals, as could be seen from several examples shown above.

It is evident that investigation of stannyl radicals is not only useful for learning more about organic derivatives of group IV B, but also of interest for the chemistry of free radicals in organic chemistry.

\section{ACKNOWLEDGEMENT}

A number of the facts given in this paper are as yet unpublished and result from the experiments of my co-workers Dr H.-J. Albert, G. Alester, U. Frommer, J. Hollaender, Dr H. Lind, Dr M. Richter, Dr K. Rübsamen, K. Schneider and Ra. Sommer. I am grateful to Dr R. Zahradnik, Institute of Physical Chemistry, Czechoslovak Academy of Sciences, Prague, for helpful discussions and HMO calculations. A part of the work reported was supported by the Deutsche Forschungsgemeinschaft, Bad Godesberg.

\section{REFERENCES}

1 H. Gilman and G. L. Schwebke, Advanc. Organometal. Chem. 1, 89 (1964), and further literature cited there.

2 W. P. Neumann and K. Kühlein, Tetrahedron Letters 1541 (1963); Liebigs Ann. Chem. 683, 1 (1965); 702, 13 (1967).

${ }^{3}$ K. Kühlein and W. P. Neumann, J. Organometal. Chem. 14, 317 (1968).

${ }^{4}$ M. Richter, Dr. rer. nat. Thesis. University of Giessen (1969).

M. Richter and W. P. Neumann. J. Organometal. Chem. 20, 81 (1969).

5 O. M. Nefedov and M. N. Manakov, Angew. Chem. 78, 1039 (1966).

6 Similar, but not such complete pictures are given for the corresponding phenyl derivatives ${ }^{3}$ Phenylated cyclosilanes have been investigated by the author's group ${ }^{3}$ and, independently, by T. H. Kinstle, I. Haiduc and H. Gilman, Inorg. Chim. Acta. In press.

6 a For proof of details, special investigation of metastable peaks is important. Current work in the author's laboratory is concerned with this.

7 T. L. Cottrell: The Strength of Chemical Bonds, 2nd edit., Butterworths: London (1958).

${ }^{8}$ K. Watanabe, J. Chem. Phys. 26, 542 (1957).

9 M. F. Lappert, J. Simpson and T. R. Spalding, J. Organometal. Chem. 17, P 1 (1969).

10 A. L. Yergey and F. W. Lampe, J. Amer. Chem. Soc. 87, 4204 (1965); J. Organometal Chem. 15, 339 (1968).

F. W. Lampe and A. Niehaus, J. Chem. Phys. 49, 2949 (1968).

11 W. P. Neumann, Angew. Chem. 81, 296 (1969). 
12 W. P. Neumann, Die Organische Chemie des Zinns. F. Enke: Stuttgart (1967). Revised English edition: The Organic Chemistry of Tin. Interscience: London (1970).

13 W. P. Neumann, H. Lind and G. Alester, Chem. Ber. 101, 2845 (1968) and further literature cited there.

${ }^{14}$ K. Rübsamen, W. P. Neumann, Ra. Sommer and U. Frommer, Chem. Ber. 102, 1290 (1969) and further literature cited there.

15 H.-J. Albert, Diploma Thesis, University of Giessen (1966).

K. Schneider, Examination Thesis, University of Giessen (1969).

16 Ch. Rüchardt, Fortschr. Chem. Forschung. 6, 251 (1966).

${ }^{17} \mathrm{H}$. Lind, Dr. rer. nat. Thesis, University of Giessen (1967).

G. Alester, Examination Thesis, University of Giessen (1967).

18 J. Hollaender, Diploma Thesis, University of Giessen (1968).

${ }^{19}$ F. Tudos and M. Azori, Acta Chim. Acad. Sci. Hungar. 34, 61 (1962).

20 J. Hollaender, unpublished work for Dr. rer. nat. Thesis, University of Dortmund (1969). 